\title{
PENERAPAN STRATEGI PQ4R UNTUK MENINGKATKAN AKTIVITAS DAN HASIL BELAJAR IPA KELAS VII-1 SMPN 4 MATARAM
}

\section{IMPLEMENTATION OF PQ4R STRATEGY TO INCREASE ACTIVITY AND LEARNING OUTCOMES OF CLASS VII-1 SMPN 4 MATARAM}

\author{
Mahyaeny \\ SMP Negeri 4 Mataram, Jalan Ade Irma Suryani No.54, Cakranegara, Kota Mataram, Lombok, Nusa Tenggara \\ Barat. 83239. Indonesia \\ Email: mahya_eny@yahoo.com
}

Diterima: 10 Desember 2017. Disetujui: 28 Maret 2018. Dipublikasikan: 31 Maret 2018

\begin{abstract}
Abstrak: Tujuan penelitian ini adalah untuk meningkatkan aktivitas dan hasil belajar Ilmu Pengetahuan Alam (IPA) siswa dengan menerapkan strategi PQ4R (Preview, Read, Reflect, Recite, Review) di kelas VII-1 SMPN 4 Mataram. Penelitian ini adalah Penelitian Tindakan Kelas yang dilaksanakan dalam dua siklus. Setiap siklus terdiri dari tahap perencanaan, tahap pelaksanaan, tahap observasi serta refleksi. Metode pengumpulan data yang digunakan dalam penelitian ini adalah observasi dan tes. Hasil penelitian menunjukkan bahwa aktivitas guru dan siswa serta hasil belajar siswa pada siklus I berada pada kategori cukup baik, cukup aktif dan ketuntasan klasikal 74\%. Siklus II aktivitas guru dan siswa meningkat menjadi baik dan aktif dengan ketuntasan klasikal mencapai $88 \%$. Dengan demikian dapat disimpulkan bahwa penerapan strategi pembelajaran PQ4R dapat meningkatkan aktivitas dan hasil belajar siswa pada mata pelajaran IPA di kelas VII-1 SMPN 4 Mataram Tahun Pelajaran 2016/2017.
\end{abstract}

Kata kunci: strategi PQ4R, hasil belajar, sains.

\begin{abstract}
The aim of this study is to improve the activity and learning achievement of science stuedent by applying PQ4R (Preview, Read, Reflect, Recite, Review) strategy in class VII-1 SMPN 4 Mataram. This research is a classroom action research which is carried out in two cycles. Each cycle consists of the planning stage, the stage of action, the observation phase and reflection. Data collection method used in this research is observation and test. The results showed that the activities of teachers and students learning achievement in cycle I are in good enough category, enough active and the classical learning achievement $74 \%$. In cycle II the activities of teachers and students increased to be good and active with the classical learning achievement $88 \%$. In conclusion, the implementation of PQ4R learning strategy improve student's activity and learning achievement in science in class VII-1 SMPN 4 Mataram Lesson Year 2016/2017.
\end{abstract}

Keywords: PQ4R strategy, learning outcomes, Science.

\section{PENDAHULUAN}

IPA adalah mata pelajaran yang penting dan erat kaitannya dengan kehidupan umat manusia. Mata pelajaran IPA merupakan salah satu mata pelajaran yang mempunyai fungsi, tujuan, dan ruang lingkup tersendiri, serta mempunyai peran yang luas dalam semua aktivitas kehidupan manusia. Kegiatan-kegiatan manusia dalam memenuhi kebutuhannya tidak terlepas dan berkaitan erat dengan IPA Melalui pembelajaran dan pengembangan potensi diri pada pembelajaran IPA siswa akan memperoleh bekal pengetahuan, keterampilan, dan sikap yang diperlukan untuk memahami dan menyesuaikan diri terhadap fenomena dan perubahan-perubahan di lingkungan sekitar dirinya, disamping memenuhi keperluan untuk melanjutkan pendidikan ke jenjang yang lebih tinggi [1,2]

Keberhasilan pembelajaran IPA ditentukan oleh beberapa faktor yaitu kemampuan guru dan kemampuan siswa itu sendiri dalam melaksanakan proses pembelajaran IPA [3]. Persoalan yang timbul ialah bagaiamana cara guru menciptakan serta mengatur situasi yang memungkinkan siswa melakukan proses belajar sehingga bisa berubah tingkah lakunya dalam proses pembelajaran. Hal ini menyangkut masalah belajar, yakni kegiatan dan pekerjaan yang harus dilakukan guru dalam proses pengajaran. Sudjana [4] menjelaskan bahwa mengajar merupakan suatu proses, yakni proses mengatur, mengorganisasi lingkungan yang ada disekitar siswa sehingga dapat menumbuhkan dan mendorong siswa melakukan proses belajar. Hal ini berarti bahwa berhasil tidaknya pencapaian tujuan pendidikan banyak bergantung kepada bagaimana proses belajar mengajar dirancang dan dijalankan secara profesional.

Mengingat pentingnya pembelajaran IPA, maka perlu diupayakan persiapan-persiapan pembelajaran yang cukup matang, diantaranya menyiapkan tujuan pembelajaran, materi atau bahan 
ajar, siswa yang menerima pelajaran, guru, strategi atau metode yang tepat, situasi, evaluasi, serta pengelolaan kelas yang baik yang dilaksanakan oleh guru maupun oleh siswa di dalam kelas [5].

Hasil observasi di SMPN 4 Mataram, pola pembelajaran IPA masih berlangsung secara konvensional sehingga pembelajaran berlangsung satu arah. Guru menjadi sentral di kelas, aktivitas guru lebih menonjol daripada siswa. Siswa di dalam kelas hanya mendengar, mencatat, dan melakukan kegiatan yang sesuai dengan perintah guru. Selain itu juga, siswa sulit dalam menerima meteri yang diberikan serta kurangnya antusias siswa dalam bertanya, menanggapi atau menyampaikan pendapat pada saat pembelajaran berlangsung. Hasil observasi di SMPN 4 Mataram khususnya di kelas VII-1 diketahui bahwa selain aktivitas belajar siswa yang rendah, hasil belajar siswa kelas VII-1 pada mata pelajaran IPA juga rendah. Berdasarkan data dari 27 orang siswa sampel, hanya 10 orang siswa yang mencapai ketuntasan belajar yang memperoleh nilai $\geq 75$ dengan persentase pencapaian klasikal $37 \%$. Angka ini belum mencapai target ketuntasan klasikal yang telah ditetapkan oleh badan pendidikan nasional, yaitu belajar dikatakan tuntas secara klasikal apabila $\geq 85 \%$ siswa mencapai KKM yang telah ditetapkan [5].

Berdasarkan hasil observasi tesebut, guru kurang menggunakan strategi atau metode yang bervariasi yang dapat menarik perhatian siswa. Penggunaan strategi atau metode tidak berdasarkan pada analisis kesesuaian antara tipe isi pelajaran dengan tipe kinerja (perfomansi) yang menjadi sasaran belajar. Strategi pembelajaran haruslah sesuai dengan materi/isi pelajaran yang diajarkan, supaya terjadi keselarasan antara proses belajar dengan perfoma yang dibutuhkan oleh siswa (Sanjana, 2006). Melihat kondisi yang demikian, maka sangat jelas dampaknya terhadap aktivitas dan hasil belajar siswa yang rendah. Untuk itu diharapkan agar guru memilih strategi atau metode pembelajaran yang lebih tepat untuk memperbaiki kualitas pembelajaran IPA siswa guna mencapai hasil yang lebih baik [7-9].

Upaya yang dapat digunakan untuk meningkatkan aktivitas dan hasil belajar adalah dengan melakukan inovasi pembelajaran dengan menerapkan strategi atau metode pembelajaran yang diharapkan mampu melibatkan siswa untuk aktif dalam proses pembelajaran (Hamalik, 2010). Menurut Sudarman [10] ada banyak strategi pembelajaran yang mampu mengaktifkan siswa dalam proses pembelajaran, salah satu strategi tersebut adalah strategi PQ4R (Preview, Question, Read, Reflect, Recite, and Review). PQ4R merupakan strategi yang digunakan untuk membantu siswa mengingat apa yang mereka baca dan dapat membantu proses belajar mengajar di kelas yang dilaksanakan dengan kegiatan membaca buku. Strategi ini termasuk dalam strategi elaborasi.
Strategi elaborasi membantu memindahkan informasi baru dari memori jangka pendek ke memori jangka panjang dengan menciptakan gabungan dan hubungan antara informasi baru dengan apa yang telah diketahui [11]. Dengan strategi ini, diharapkan proses pembelajaran menjadi lebih baik, sehingga aktivitas dan hasil belajar siswa khususnya pada mata pelajaran IPA menjadi meningkat. Pada penelitian ini strategi PQ4R diterapkan dalam meningkatkan aktivitas dan hasil belajar siswa pada mata pelajaran IPA kelas VII-1 SMPN 4 Mataram Tahun Pelajaran 2016/2017.

\section{METODE PENELITIAN}

Jenis penelitian ini adalah penelitian tindakan kelas, yang dilaksanakan pada semester ganjil tahun pelajaran 2016/2017. Subjek dalam penelitian ini adalah seluruh siswa kelas VII-1 SMPN 4 Mataram Tahun Pelajaran 2016/2017 yang berjumlah 27 orang siswa, terdiri dari 12 orang siswa laki-laki dan 15 orang siswa perempuan. Penelitian tindakan kelas dapat dilakukan beberapa siklus [12]. Penelitian tindakan kelas ini dilaksanakan dalam 2 siklus. Masing-masing siklus terdiri dari 4 komponen, yaitu: (1) Perencanaan (Planning); (2) Tindakan (Acting); (3) Pengamatan (Observing) dan evaluasi; dan (4) Refleksi [13].

\section{HASIL PENELITIAN DAN PEMBAHASAN}

Menerapkan strategi PQ4R berdasarkan tahapan inti dengan menggunakan bahan bacaan dari materi. Tahapannya yaitu memberikan bahan bacaan kepada siswa untuk di baca secara sepintas materi pembelajaran dalam kegiatan Preview. Siswa memperhatikan ide pokok bahan bacaan yang di baca dan siswa membuat pertanyaan sendiri dalam kegiatan Question. Kemudian memberi tugas kepada siswa untuk membaca dan menjawab pertanyaan yang telah di buat siswa dalam kegiatan Read (Rl). Mengaitkan antara bahan bacaan dengan pengetahuan yang dimiliki sebelumnya dalam kegiatan Reflect (R2). Kemudian siswa membuat intisari dari materi yang telah dipelajari dalam kegiatan Recite (R3). Setelah itu siswa membaca intisari yang telah di buatnya dan apa yang ada di benaknya, jika belum yakin siswa di minta membaca materi kembali dalam kegiatan Review (R4).

Setelah itu guru membagi siswa menjadi 6 kelompok, masing-masing kelompok terdiri dari 4-5 orang, dan memberikan LKS kepada masing-masing kelompok. Guru memberikan pengarahan mengenai apa yang harus dilakukan terkait dengan LKS tersebut dan bertugas untuk membimbing kelompok yang mengalami kesulitan. Pada saat mendiskusikan LKS, ada anggota kelompok yang tidak membantu teman satu kelompoknya yang mengalami kesulitan karena sibuk-sibuk sendiri. Selain itu, kerjasama siswa dalam kelompoknya kurang terjalin dengan baik disebabkan karena tidak adanya keterbukaan di 
antara masing-masing anggota kelompok, selain itu ada kelompok yang anggotanya tidak mengerjakan LKS karena didominasi oleh beberapa anggota kelompoknya saja. Setelah semua kelompok mengerjakan LKS, guru menyuruh perwakilan setiap kelompok untuk mempersentasikan hasil diskusi, kemudian meminta agar diakhir diskusi semua kelompok mencatat atau membuat rangkuman dari hasil presentasi. Dari kegiatan presentasi kelompok ini, guru memberikan penghargaan berupa pujian.

Kegiatan akhir diawali dengan memberikan kesempatan kepada siswa untuk bertanya jika ada materi yang belum dipahami dan membimbing siswa untuk menyimpulkan materi. Namun hanya beberapa siswa yang mau menyimpulkan materi itupun karena ditunjuk oleh guru. Pada saat memberikan kesimpulan suasana kelas menjadi ribut dan siswa tidak tertib dan menggangu temannya, disebabkan karena siswa melihat ada kelas lain yang sudah keluar main. Untuk mengatasi keributan tersebut dan menegur untuk tidak mengulanginya lagi. Sebelum menutup kegiatan pembelajaran guru memberikan penguatan mengenai materi yang diajarkan. Selanjutnya guru mengakhiri pelajaran dengan mengucapkan salam dan menginformasikan bahwa pertemuan selanjutnya akan diadakan ulangan.

Evaluasi dilaksanakan pada akhir siklus, yaitu pada pertemuan kedua. Hal ini bertujuan untuk mengetahui apakah siswa sudah memahami dengan baik materi yang telah dipelajari. Untuk mengetahui hasil belajar siswa digunakan tes evaluasi dalam bentuk pilihan ganda. Adapun setelah diolah ringkasan hasil evaluasi siklus I, dapat dilihat pada Tabel 1.

Tabel 1. Ringkasan Hasil Evaluasi Belajar Siklus I

\begin{tabular}{clc}
\hline No. & \multicolumn{1}{c}{ Aspek } & Skor \\
\hline 1. & Jumlah siswa yang mengikuti tes & 27 \\
2. & Nilai tertinggi & 90 \\
3. & Nilai terendah & 70 \\
4. & Nilai rata-rata & 77,4 \\
5. & Jumlah siswa yang tuntas & 20 \\
6. & Jumlah siswa yang tidak tuntas & 7 \\
7. & Persentase ketuntasan & $74 \%$ \\
\hline
\end{tabular}

Tabel 2. Ringkasan Hasil Evaluasi Belajar Siklus II

\begin{tabular}{clc}
\hline No. & \multicolumn{1}{c}{ Aspek } & Skor \\
\hline 1. & Jumlah siswa yang mengikuti tes & 27 \\
2. & Nilai Tertinggi & 100 \\
3. & Nilai Terendah & 70 \\
4. & Rata-Rata & 82,5 \\
5. & Jumlah siswa tuntas & 24 \\
6. & Jumlah siswa tidak tuntas & 3 \\
7. & Persentase Ketuntasan & $88 \%$ \\
\hline
\end{tabular}

Tabel 3. Data Hasil Evaluasi dan Hasil Observasi dalam strategi PQ4R Siklus I dan II.

\begin{tabular}{|c|c|c|c|c|c|c|c|}
\hline \multirow[b]{2}{*}{ Penelitian } & \multirow{2}{*}{$\begin{array}{c}\text { Rata-Rata } \\
\text { Skor hasil } \\
\text { belajar } \\
\text { Siswa }\end{array}$} & \multirow{2}{*}{$\begin{array}{c}\text { Ketuntasan } \\
\text { klasikal }\end{array}$} & \multicolumn{2}{|c|}{ Aktivitas Siswa } & \multicolumn{2}{|c|}{ Kegiatan Guru } & \multirow{2}{*}{$\begin{array}{c}\text { Indikator } \\
\text { keberhasilan }\end{array}$} \\
\hline & & & $\begin{array}{c}\text { Rata-rata } \\
\text { Skor }\end{array}$ & Kategori & $\begin{array}{c}\text { Rata-rata } \\
\text { skor }\end{array}$ & Kategori & \\
\hline $\begin{array}{c}\text { PTK } \\
\text { (Siklus I) }\end{array}$ & 77,4 & $74 \%$ & 16.8 & $\begin{array}{l}\text { Cukup } \\
\text { Aktif }\end{array}$ & 20.3 & $\begin{array}{l}\text { Cukup } \\
\text { Baik }\end{array}$ & $\begin{array}{c}\text { Belum } \\
\text { Tercapai } \\
(74 \%)\end{array}$ \\
\hline $\begin{array}{c}\text { PTK } \\
\text { (Siklus II) }\end{array}$ & 82,5 & $88 \%$ & 20.1 & Aktif & 25.8 & Baik & $\begin{array}{c}\text { Tercapai } \\
(88 \%)\end{array}$ \\
\hline
\end{tabular}

Pada tahapan evalusi siklus I, tes essay yang diberikan sebanyak 3 butir soal dan dilaksanakan dengan alokasi waktu 1 x 35 menit. Dari analisis hasil evaluasi siklus I diperoleh ratarata skor siswa adalah 77,4 dengan nilai tertinggi 90 dan nilai terendah 70. Persentase ketuntasan klasikal mencapai $74 \%$ yang menunjukkan bahwa hasil belajar siswa pada siklus I ini belum mencapai indikator kerja yaitu persentase ketuntasan klasikal minimal $85 \%$. Oleh karena itu, penelitian dilanjutkan ke siklus berikutnya yaitu ke siklus II. 
Evaluasi kembali dilaksanakan pada akhir siklus II. Hal ini bertujuan untuk mengetahui apakah siswa sudah memahami dengan baik materi yang telah dipelajari. Seperti pada siklus I, Tes evaluasi yang diberikan pada siklus II juga dalam bentuk tes. Adapun ringkasan hasil evaluasi siklus II, dapat dilihat pada Tabel 2 .

Dari analisis hasil evaluasi siklus II diperoleh data bahwa terjadi peningkatan rata-rata skor evaluasi siswa dari siklus I ke siklus II yaitu dari 77,4 ke 82,5 Walaupun peningkatan rata-rata skor evaluasi siswa tidak terlalu signifikan, namun pada siklus II ini ketuntasan belajar siswa mencapai $88 \%$ yang menunjukkan bahwa indikator penelitian untuk hasil belajar siswa telah tercapai (minimal $85 \%$ siswa memperoleh nilai $\geq 75$ ). Adapun ringkasan dari hasil penelitian pada siklus I, dan siklus II yang memuat rata-rata skor hasil belajar siswa, aktivitas siswa, dan aktivitas guru disajikan pada Tabel 3 .

Hasil pada siklus II ini mengalami peningkatan lebih baik dari siklus I. Adanya peningkatan hasil belajar pada siklus II ini dipengaruhi oleh adanya peningkatan kemampuan guru dalam menerapkan strategi pembelajaran PQ4R sebagai strategi pembelajaran di dalam proses pembelajaran. Dari segi siswa peningkatan ini terjadi karena dalam diri siswa timbul rasa senang, aktif, termotivasi dan keterampilan siswa karena diberikan suatu bahan bacaan langsung yang dapat mereka baca dan ingat sendiri, sehingga siswa mendapatkan konsep yang utuh tentang materi pembelajaran, dan memudahkan mereka memahami materi pembelajaran. Dari hasil siklus II, penelitian tindakan kelas ini dikatakan berhasil karena sudah mencapai semua indikator ketercapaian.

\section{KESIMPULAN}

Berdasarkan data hasil penelitian tindakan kelas yang telah dilakukan dalam dua siklus, proses pembelajaran dengan menerapkan strategi PQ4R terjadi peningkatan, baik dari aktivitas guru dan siswa serta hasil belajar siswa, hal ini ditunjukkan dengan terjadinya peningkatan dari siklus I hingga siklus II, aktivitas guru dan siswa berada pada kategori cukup baik dan cukup aktif hingga pada siklus II aktivitas guru dan siswa meningkat menjadi baik dan aktif, serta ketuntasan klasikal masing masing disetiap siklus, yaitu $74 \%$ dan $88 \%$. Dengan demikian dapat disimpulkan bahwa penerapan strategi pembelajaran PQ4R (Preview, Read, Reflect, Recite, Review) dapat meningkatkan aktivitas dan hasil belajar siswa pada mata pelajaran Ilmu Pengetahuan Alam (IPA) di kelas VII-1 SMPN 4 Mataram Tahun Pelajaran 2016/2017.

\section{DAFTAR PUSTAKA}

1. Jufri, A. W., \& Hikmawati, H. (2014). Analisis Kemelekan Sains (Science Literacy) Dan Kemelekan Inkuiri (Inquiry Literacy) Guru
Mata Pelajaran IPA SMP. Jurnal Pijar Mipa, 9(1).

2. Toharudin, U., Hendrawati, S., \& Rustaman, A. (2011). Membangun literasi sains peserta didik. Bandung: Humaniora.

3. Ilhamdi, M. L. (2012). Model pembelajaran berbasis peta konsep dan handout untuk meningkatkan prestasi belajar IPA biologi siswa kelas I SMPN 4 Lingsar Lombok Barat, Jurnal Pijar, Volume 2(1)

4. Sudjana, N. 2009. Dasar-Dasar Proses Balajar Mengajar. Bandung: Sinar Baru Algensindo.

5. Aqib, Z. 2003. Profesionalisme Guru dalam Pembelajaran. Surabaya: Insan Cendekia.

6. Mulyasa, E. 2007. Kurikulum Tingkat Satuan Pendidikan. Bandung. Penerbit Rosda

7. Mahyaeny, M. (2016). Peningkatan Hasil Belajar Siswa Melalui Strategi Pembelajaran Discovery Pada Mata Pelajaran IPA Biologi Kelas VII-5 SMPN 4 Mataram. Jurnal Pijar Mipa, 11(1).

8. Mahyaeny, M. (2015). Penerapan Model Pembelajaran Kooperatif Tipe TPS (Think Pair Share) Untuk Meningkatkan Aktivitas Belajar IPA Biologi Kelas VIII. 5 SMPN 4 Mataram. Jurnal Pijar Mipa, 10(2).

9. Retnowati, E., \& Jailani, J. (2009). Implementasi Teknik Jigsaw Dalam Pembelajaran Geometri Sebagai Upaya Meningkatkan Hasil Belajar dan Kemandirian Belajar Siswa Kelas IX SMU Negeri 1 Depok Yogyakarta. Jurnal Pijar Mipa, 4(1).

10. Wahyuningsih, A. N. (2012). Pengembangan media komik bergambar materi sistem saraf untuk pembelajaran yang menggunakan strategi PQ4R. Journal of Innovative Science Education, 1(1).

11. Trianto. 2007. Model-Model Pembelajaran Inovatif Berorientasi Konstruktivistik. Jakarta: Prestasi Pustaka Publisher

12. Kunandar. 2011. Langkah Mudah Penelitian Tindakan Kelas Sebagai Pengembangan Profesi Guru. Jakarta: Rajawali Pers.

13. Arikunto, S. 2010. Penelitian Tindakan Kelas. Jakarta: PT. Bumi Aksara. 